\title{
Atmospheric response to the autumn sea-ice free Arctic and its detectability
}

\author{
Lingling Suo ${ }^{1} \cdot$ Yongqi Gao ${ }^{1,2} \cdot$ Dong $\mathrm{Guo}^{3}$. \\ Jiping Liu ${ }^{4} \cdot$ Huijun Wang ${ }^{2} \cdot$ Ola M. Johannessen ${ }^{1,2,5}$
}

Received: 28 August 2014 / Accepted: 25 May 2015 / Published online: 10 June 2015

(C) The Author(s) 2015. This article is published with open access at Springerlink.com

\begin{abstract}
We have used an Atmospheric General Circulation Model with a large ensemble (300) to explore the atmospheric responses during the autumn-winter (September to February) to the projected sea-ice free Arctic in autumn (September to November). The detectability of the responses against the internal variability has also been studied. Three ensemble experiments have been performed, the control (CONT) forced by the simulated present-day Arctic sea-ice concentration (SIC) and sea surface temperature (SST), the second forced by the projected autumn Arctic SIC free and present-day SSTs (SENSICE) and the third forced by the projected autumn Arctic SIC free and projected SSTs (SENS). The results show that the disappearance of autumn Arctic sea-ice can cause significant synchronous near-surface warming and increased precipitation over the regions where the sea-ice is removed. The changes in autumn surface heat flux (sensible plus latent), surface air temperature (SAT) and precipitation averaged over the sea-ice reduction region between the SENS and
\end{abstract}

Lingling Suo

lingling.suo@nersc.no

1 Nansen Environmental and Remote Sensing Center and Bjerknes Center for Climate Research,

Thormøhlens gate 47, 5006 Bergen, Norway

2 Nansen-Zhu International Reserach Center, Institute of Atmospheric Physics, Chinese Academy of Sciences, Beijing 100029, China

3 Climate Change Research Center, Chinese Academy of Sciences, Beijing 100029, China

4 Department of Atmospheric and Environmental Sciences, University at Albany, State University of New York, Albany, NY, USA

5 Nansen Scientific Society, Bergen, Norway the CONT are about 46, 43 and $50 \%$ more respectively than the changes between the SENSICE and the CONT, which is consistent with the prescribed boundary setting: the surface temperature warming averaged over the sea-ice reduction region in the SENS relative to the CONT is $48 \%$ higher than that in the SENSICE relative to the CONT. The response shows a significant negative Arctic Oscillation (AO) in the troposphere during autumn and December. However, the negative AO does not persist into JanuaryFebruary (JF). Instead, $500 \mathrm{hPa}$ geopotential height (GH) response presents a wave train like pattern in JF which is related to the downstream propagation of the planetary wave perturbations during November-December. The SAT increases over northern Eurasia in JF in accordance with the atmosphere circulation changes. The comparison of the atmosphere response with the atmosphere internal variability (AIV) shows that the responses of SAT and precipitation in the Arctic far exceed the AIV in autumn and the response of the $500 \mathrm{hPa} \mathrm{GH}$ is comparable to the AIV in autumn, but none of the responses during JF exceeds the AIV.

Keywords Ice-free Arctic - Atmosphere response · Internal variability $\cdot$ Teleconnection

\section{Introduction}

The Arctic sea-ice has declined dramatically since 1979 (Johannessen et al. 2004; Comiso et al. 2008; Screen et al. 2013). Future climate projections by Coupled Model Intercomparison Project Phase 5 (CMIP5) models indicate that the Arctic Ocean would likely be sea-ice free in autumn at mid-twenty first century (Liu et al. 2013) or even earlier (Overland and Wang 2013). Sea-ice plays an important role in the climate system because of its high albedo, 
blocking of air-sea heat and moisture flux, and potential effect on ocean circulation. However, the dynamic-thermodynamic atmosphere response to the sea-ice reduction is not straightforward.

Early observational and modeling studies showed that the observed autumn Arctic sea-ice reduction has an impact on the atmosphere in autumn. The warmer ocean associated with the autumn sea-ice reduction can transfer more heat to the atmosphere (Blüthgen et al. 2012), cause the low-troposphere warming (Kumar et al. 2010; Blüthgen et al. 2012; Screen et al. 2014), moistening (Liu et al. 2012; Screen et al. 2013) and the changes in sea level pressure (SLP) over the Arctic (Screen et al. 2014). The neutral or negative North Atlantic Oscillation (NAO) pattern can appear simultaneously in response to the summer-autumn sea-ice reduction (Francis et al. 2009; Screen et al. 2013; Walsh 2014).

Early studies also suggested that the winter surface air temperature (SAT) and the snowfall over northern continents were closely associated with the reduction of observed autumn Arctic SIC. For example, it has been proposed that the Eurasia cold winter (Honda et al. 2009), spring cooling over East Asia (Li and Wang 2013a), precipitation ( $\mathrm{Li}$ and Wang 2013b) and intense snowfall over the North America, Europe and East Asia in recent winters (Liu et al. 2012; Na et al. 2012) can be attributed to the reduced autumn Arctic SIC, either by the intensified and more persistent winter Siberian High or the increased winter blockings (Wu et al. 2011; Liu et al. 2012; Zhang et al. 2012). But the causality of the autumn Arctic SIC reduction and the winter weather events has not been proven and clearly explained yet. In previous simulation studies, the winter weather pattern responses to the Arctic SIC reduction have been diverse, which has prevented a clear conclusion (Bader et al. 2011; Vihma 2014).

Some studies argued that the negative Arctic Oscillation (AO) resembling pattern in autumn can persist into winter (Francis et al. 2009; Liu et al. 2012; Li and Wang 2013b) whereas some other studies suggested that the autumn atmospheric response cannot persist into the mid-late winter (e.g., Blüthgen et al. 2012; Screen et al. 2013). Furthermore, Screen et al. (2014) investigated the winter atmospheric response to the autumn Arctic sea-ice concentration (SIC) trend from 1979 to 2009 using two models and did not find the negative AO or NAO pattern. Actually, the SLP response in the National Center for Atmospheric Research Community Atmosphere Model version 3 (CAM3) projected a positive phase of the AO. That contrasts with the negative AO-resembling SLP response based on the observational analysis and model (CAM3.1) simulation in Liu et al. (2012).

The diversity of the simulated responses could come from several factors: the first is the atmosphere internal variability (AIV). AIV can partially or fully mask out the atmosphere responses to the observed reduction in Arctic SIC as proposed by previous studies (e.g., Kumar et al. 2010; Screen et al. 2013, 2014). In Wu et al. (2013), only 5 of the 12 numerical experiments forced by the observed Arctic SIC from 1978 to 2007 can weakly reproduce the observed SAT and atmospheric circulation anomalies. Similarly, Honda et al. (2009) used 28 of total 50 numerical experiments to investigate the autumn Arctic SIC impact on the Eurasia cold winter. They claimed that the SAT response to sea-ice anomalies would be weak if all 50 members were used. Screen et al. (2014) pointed out that a large ensemble is required to address uncertainties due to AIV.

Additionally, the boundary conditions used in the aforementioned modeling studies are different, which is another reason for the diverse results. For example, the Arctic SIC and the associated sea surface temperature (SST) changes during the whole year were used to force the model in Screen et al. (2014), whereas only the autumn and partly winter (persisting from autumn) SIC changes and no SST changes were used to force the model in Liu et al. (2012). Some previous studies proposed the linkage of the autumn Arctic SIC reduction and the winter atmospheric responses based on the simulations in which not only the autumn but also the winter Arctic SIC reductions are included in the boundary conditions (e.g. Liu et al. 2012; Li and Wang 2013b). The winter Arctic SIC reduction can also have an impact on the winter atmosphere circulation (Tang et al. 2013), so that the simulated winter atmospheric responses in these studies contain both the possible lagged responses to the autumn SIC reduction and the changes caused by the winter SIC reduction. In order to find out if the autumn SIC reduction can have a prominent impact on the winter atmosphere, a study based on simulations in which only the autumn Arctic SIC is reduced is needed.

There are also some studies which address the atmosphere responses to the projected sea-ice free Arctic. Deser et al. (2010) showed the simulated atmospheric response to the projected sea-ice for all seasons (the Arctic Ocean is nearly sea-ice free in September-October). They found an intensified Siberian High during November-December, negative AO during January-February (JF) and increased winter precipitation over northern Eurasia and North America. Peings and Magnusdottir (2014) also reported a winter $500 \mathrm{hPa}$ negative AO pattern in response to the projected Arctic SIC (nearly ice-free in September). However, there is still the problem that the change in winter atmospheric circulation cannot be solely attributed to the autumn or winter sea-ice reduction clearly since the projected Arctic SIC was significantly reduced in all months in their numerical experiments.

The impact of the projected sea-ice free Arctic in autumn on the autumn-winter atmosphere is also discussed in this 
study. In order to clarify if there is a significant lagged winter atmosphere response to autumn Arctic sea-ice free conditions, simulations in which Arctic SIC is reduced only in autumn have been performed. There are three groups of experiments: control, simulations with perturbed autumn Arctic SIC and simulations with perturbed autumn Arctic SIC and SST. The experiments with the prescribed present and projected autumn Arctic SST were compared to find out if the prescribing of Arctic SST can have a significant impact on the autumn-winter atmospheric responses. And the detectability of the simulated atmospheric responses compared with the AIV is also discussed. In order to better facilitate an estimate of AIV and to reduce the uncertainty in atmospheric response, we performed a large ensemble of simulations including 300 ensemble members.

The rest of the paper is organized as follows: A description of the model and model simulations is presented in Sect. 2. The autumn-winter atmospheric response to the projected autumn sea-ice-free Arctic and the detectability of the responses are presented in Sect. 3. Finally, discussions and conclusions are presented in Sect. 4.

\section{Data and methods}

We have used the Atmospheric General Circulation Model (AGCM) ARPEGE Climat3 to explore the atmospheric response to the projected autumn Arctic sea-ice reduction. ARPEGE, the atmosphere component of the Bergen Climate Model version 2 (BCM2; Otterå et al. 2009) was developed at METEO-FRANCE (Déqué et al. 1994). The ARPEGE is run with a truncation at wave number 63 (TL63), a time step of $1800 \mathrm{~s}, 31$ vertical levels rang-ing from the surface to $0.01 \mathrm{hPa}$ and a horizontal resolution of approximately $2.8^{\circ}$. The ocean component of the BCM2 is the MICOM (Bleck et al. 1992). The BCM2 can reproduce the twentieth century climate (SAT and sea-ice cover) in the Arctic with reasonable accuracy (Suo et al. 2013).

The boundary conditions for the ARPEGE simulations are based on the existing BCM2 present climate (Con$\mathrm{tBCM}$ ) and future projection (ProjBCM) simulations. The ContBCM is a 380 -year experiment with the concentrations of all green house gases fixed at the level from the year 2000 and the ProjBCM is forced by increasing $\mathrm{CO}_{2}(1 \%$ per year) starting from $367 \mathrm{ppm}$ (the year 2000 level). In the ProjBCM, when $\mathrm{CO}_{2}$ concentration reaches $992 \mathrm{ppm}$, the Arctic Ocean is free of sea-ice during September and October. Then, the ProjBCM continues for 20 years with fixed 992 ppm $\mathrm{CO}_{2}$ concentration. Daily sea-ice area (SIA) is below 0.1 million $\mathrm{km}^{2}$ during September and October in the last 20 years of the ProjBCM. That is far lower than 1 million $\mathrm{km}^{2}$ which is used as the threshold to define the nearly ice-free Arctic in previous studies (Liu et al. 2013; Overland and Wang 2013).

The daily boundary (SIC and SST) conditions for the control run (CONT) performed with the ARPEGE are the mean of the stable 100 year integration in the ContBCM (Fig. 1a). The CONT contains 300 year simulation forced by yearly repeating daily SST and SIC. In the CONT, the solar irradiation is kept constant and greenhouse gases are
Fig. 1 a Daily Arctic sea-ice area in the SENSICE/SENS, the ContBCM/CONT and the ProjBCM (unit: $10^{6} \mathrm{~km}^{2}$ ); b autumn Arctic SIC differences between the SENSICE/SENS and the CONT and autumn surface temperature differences (unit: ${ }^{\circ} \mathrm{C}$ ) relative to the CONT in $\mathbf{c}$ the SENSICE and $\mathbf{d}$ the SENS

(a)

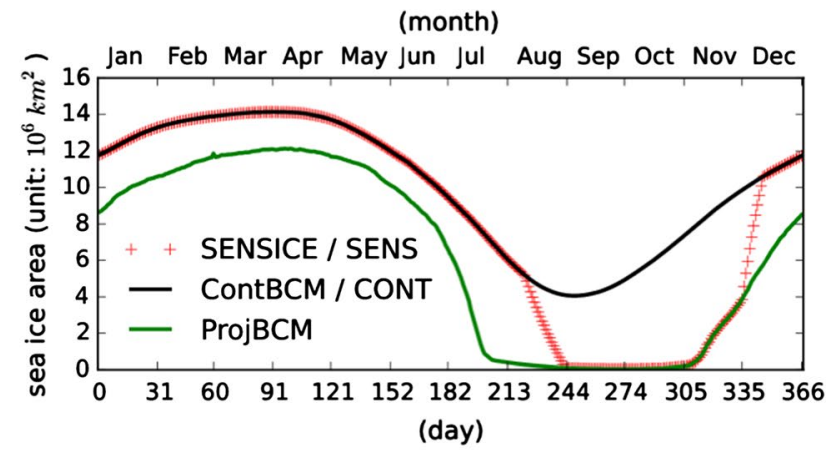

(b)

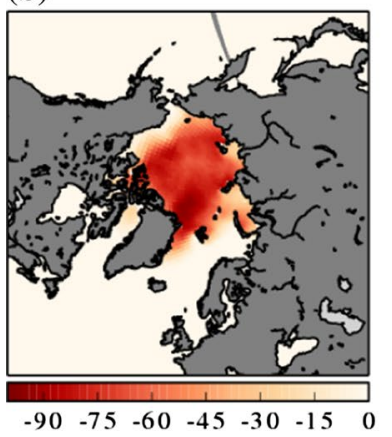

(c)

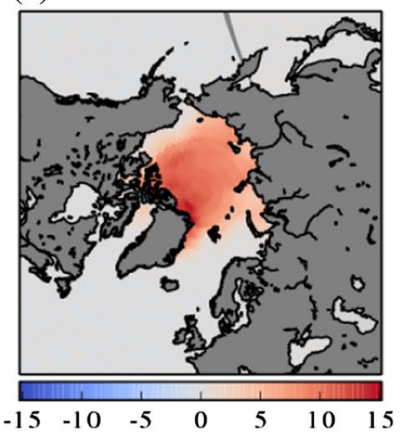

(d)

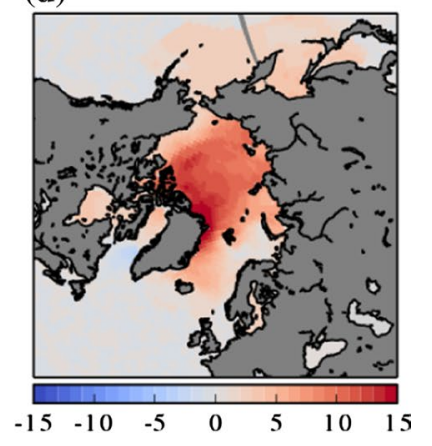


(a)

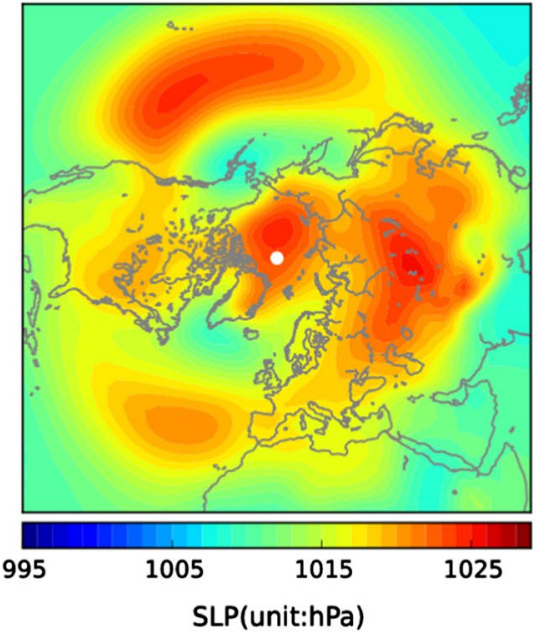

(b)

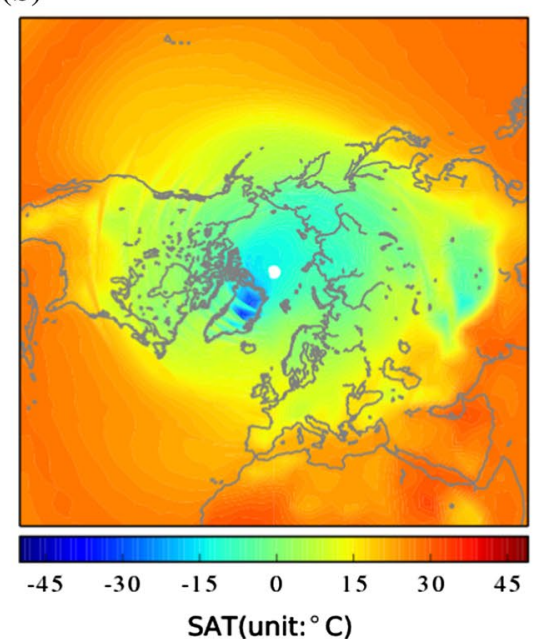

(c)

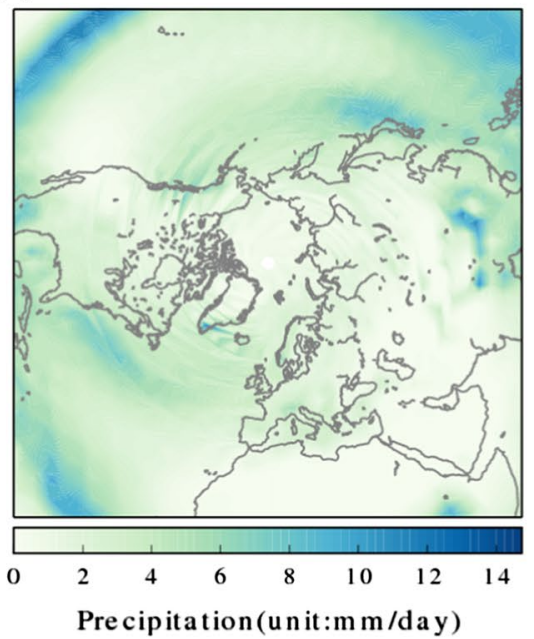

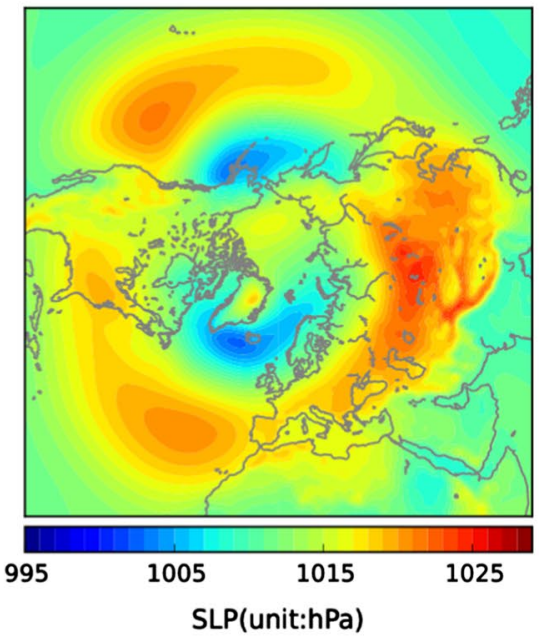
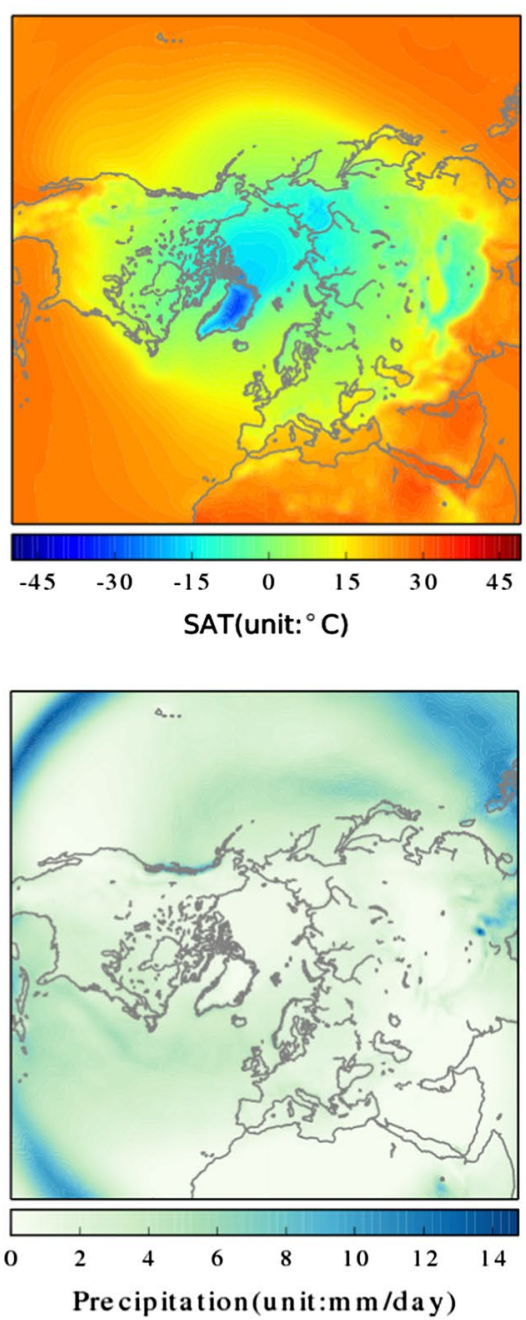
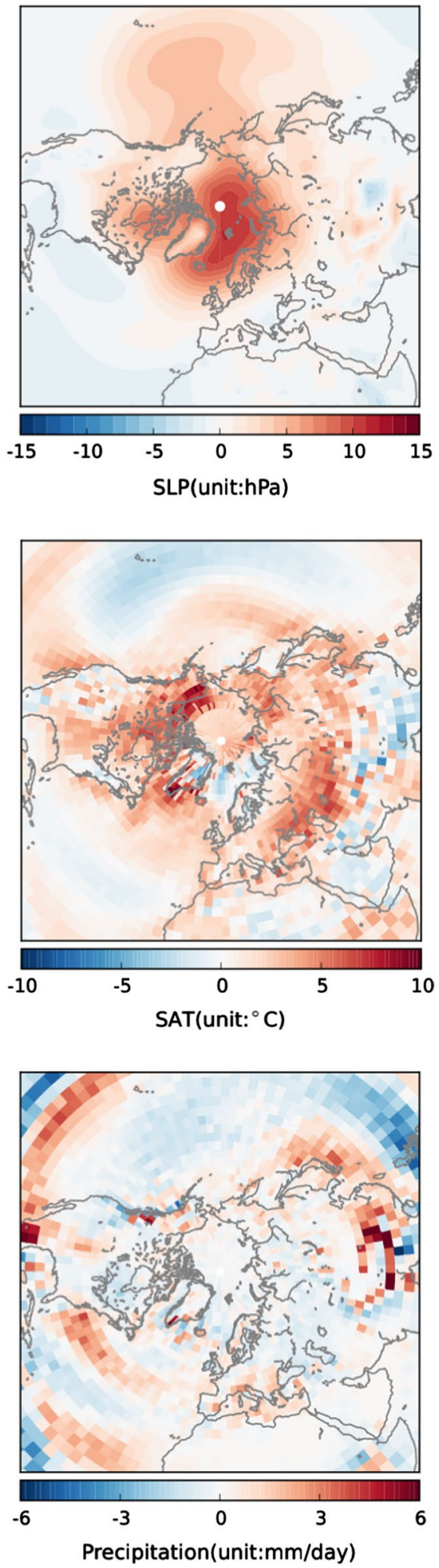

Fig. 2 The autumn a SLP (unit: hPa), b SAT (unit: ${ }^{\circ} \mathrm{C}$ ) and $\mathbf{c}$ precipitation (unit: $\mathrm{mm} /$ day) in the CONT 300 ensembles mean (left), in the ERAI (middle) and the difference (right) 
kept at the year 2000 level. Figure 2 shows the autumn SLP, SAT and precipitation simulated in the CONT ensemble mean and in the 1979-2000 mean of the ECMWF ERA-Interim (ERAI) reanalysis data (Dee et al. 2011). In general, the distribution of the simulated $20^{\circ} \mathrm{N}-90^{\circ} \mathrm{N} \mathrm{SLP}$ resembles that in the ERAI: the Icelandic low, the Aleutian low and the Siberian high are reproduced reasonably although the simulated SLP is relatively higher than that in the ERAI over the Arctic and the North Pacific. The simulated SAT also shows the reasonably reproduced southnorth gradient and the zonal variations with the coldest temperatures over Greenland although the simulated SAT at high latitudes is warmer overall than that in the ERAI. The differences between the simulated precipitation and that in the ERAI in mid-high latitudes are mostly located over the West Atlantic and East Asia where the CONT simulates more precipitation than that shown in the ERAI. Still, the simulated precipitation generally has a good agreement with the ERAI over all. Generally, the CONT shows a reasonable climatology with reference to reanalysis. The ensemble mean of the CONT is therefore used as the simulated reference climatology for obtaining the responses in sensitivity experiments.

Different methods have been used to set up SST conditions in sea-ice reduction regions in previous studies. The solar radiation arriving at the newly exposed ocean surface because of the sea-ice melting can cause SST to increase in these regions (Perovich et al. 2008). The SST increases can be ignored and the SSTs in sea-ice reduction regions can be set as constant (normally at the freezing point $-1.8^{\circ} \mathrm{C}$, e.g. in $\mathrm{Wu}$ et al. 2013). Or the increased SSTs may be prescribed as boundary conditions in sea-ice reduction regions (Peings and Magnusdottir 2014). Two sensitivity experiments: the SENSICE with Arctic SIC perturbations and the SENS with Arctic SIC and SST perturbations in autumn are performed by the ARPEGE for comparison. The differences between the SENSICE (SENS) and the CONT are that the autumn daily Arctic SIC (SIC and SST) in the SENSICE (SENS) are the last 20 year mean of the ProjBCM, and the daily SIC (SIC and SST) in the Arctic evolves gradually from the CONT to the ProjBCM during mid-late August and from the ProjBCM back to the CONT during early December (Fig. 1a). The SST in the SENSICE is the same as that in the CONT. The external forcings are the same in the SENSICE and the SENS as in the CONT.

The prescribed sea-ice thickness in the CONT, SENS and SENSICE is processed in the same way as SIC, selected from the ContBCM or the ProjBCM respectively in consistence with the selection of SIC.

The region where the projected SSTs are prescribed in the SENS is isolated as the maximum SIC coverage during the whole year in the climatology (the stable 100 year mean) simulated by the ContBCM. For stabilization of the simulation, this region is fixed and not varied daily so that it is consistent with the winter maximum SIC coverage but more extensive than the simulated autumn SIC changing region (Fig. $1 b$ and d). Then the projected SSTs prescribed in the SENS during autumn covers not only the newly exposed central Arctic Oceans because of the seaice removal (Fig. 1b) but also the Hudson Bay, the Greenland-Icelandic-Norwegian (GIN) Seas (hereafter referred to as the Atlantic marginal region), the sea of Okhotsk, the Bering Sea and the Beaufort Sea (referred to as the Pacific marginal region) which experience a seasonal variation of sea-ice coverage (Fig. 1d). The effect of including projected SSTs over the Atlantic and Pacific marginal regions is discussed in part 3.2.

Associated with removal of the sea-ice, the regional mean of the area weighted surface temperature (ST) increased over the sea-ice reduction region by about $4.2^{\circ} \mathrm{C}$ (Fig. 1c). When the SST increases are also taken into consideration, the regional mean ST increase over the sea-ice reduction region reaches up to $6.2{ }^{\circ} \mathrm{C}$ (Fig. $\left.1 \mathrm{~d}\right), 2{ }^{\circ} \mathrm{C}(48 \%)$ higher than that shown in Fig. 1c. The regional mean of the area weighted ST increase over the Pacific marginal and Atlantic marginal outside of the sea-ice reduction region are 2.6 and $2.1{ }^{\circ} \mathrm{C}$ respectively.

Each experiment (CONT, SENS and SENSICE) contains four runs which start from different initial conditions. In each run, the data in the first 5 years are abandoned in order to avoid the bias of the model spin-up. 300 years are selected from the four runs totally. Each year can be treated as an independent ensemble member because prescribed boundary conditions repeat annually and the initial conditions vary. Since there is no perturbation of the boundary conditions from mid December to early August and the atmosphere processes are short persistent, it can be treated that the autumn-winter responses in each year is independent from the responses in previous year. Similar configuration for the boundary conditions has been used in previous studies (Deser et al. 2010; Liu et al. 2012; Screen et al. 2014).

The simulated atmospheric response is defined as the difference in the ensemble means between the SENS/ SENSICE and the CONT. The two-tailed student $t$ test has been used in this study to measure the significance of the responses. The responses that pass the $95 \%$ significance level are described as 'significant'. The regional mean is calculated as the average of the area weighted responses.

The distribution spread of 300 ensemble members is dominated by the AIV. The standard deviation (SD) of the ensemble members is a measure of AIV. The detectability of the responses is measured by the ratio of the mean change to the SD. This definition of the detectability has been used as the signal (response) to noise (AIV) ratio in earlier studies (e.g., Kumar et al. 2010). 


\section{Results}

\subsection{Responses to the autumn Arctic SIC free in the SENSICE}

In response to the future projected autumn sea-ice free Arctic, the autumn surface upward heat fluxes (sensible plus latent) increase over the Arctic Ocean (Fig. 3a). The heat flux averaged over the sea-ice reduction region increases

(a)
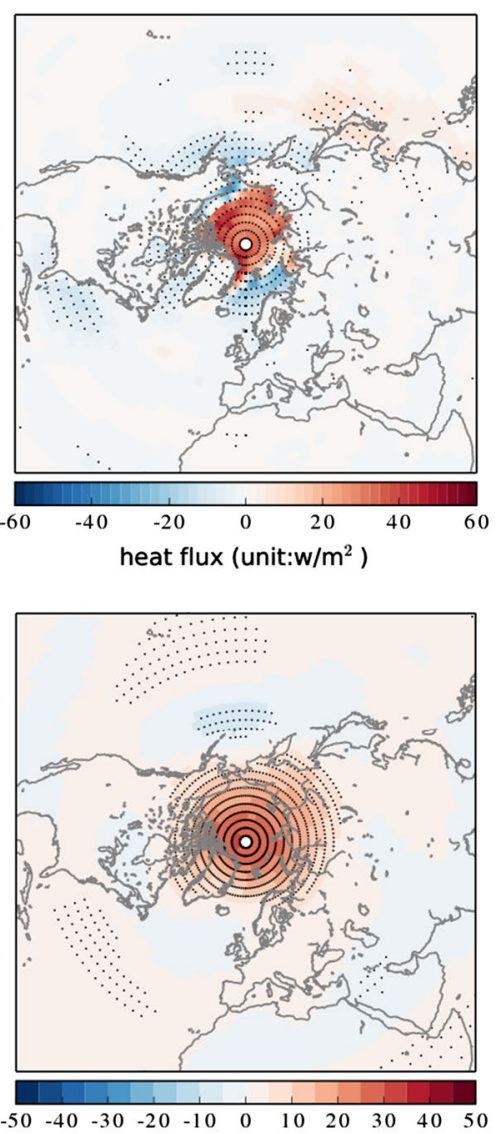

$500 \mathrm{hPa} \mathrm{GH}(\mathrm{unit}: \mathrm{m})$

(b)

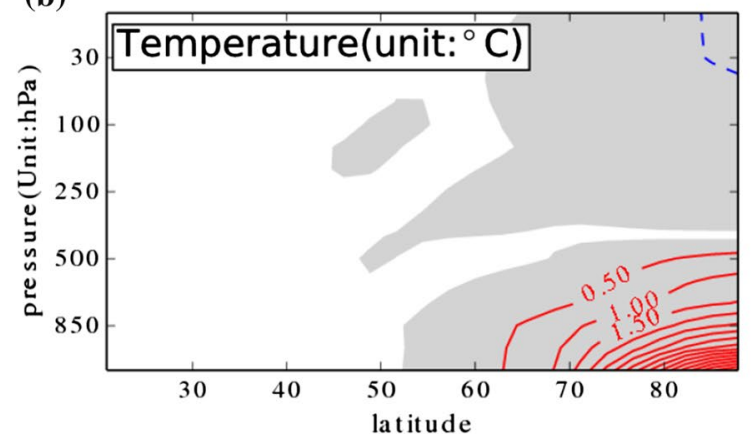

Fig. 3 The simulated autumn a surface heat flux (latent add sensible, positive means atmosphere gain), SAT, $500 \mathrm{hPa}$ geopotential height $(\mathrm{GH})$ and precipitation responses and $\mathbf{b}$ zonal mean temperature and geopotential height $(\mathrm{GH})$ responses in the SENSICE. The black dots around $11.5 \mathrm{~W} / \mathrm{m}^{2}$. Associated with these significant enhanced heat fluxes, the near surface warming appears (Fig. 3a), around $4.6{ }^{\circ} \mathrm{C}$ averaged over the sea-ice reduction region. When the heat flux increases are localized over the region with sea-ice loss, the warming is extended to the northern edge of the adjacent continents possibly because of the warmed atmosphere advection. The warming in the region outside of but adjacent to sea-ice loss can reduce the ocean-air temperature gradient (the SSTs there are fixed
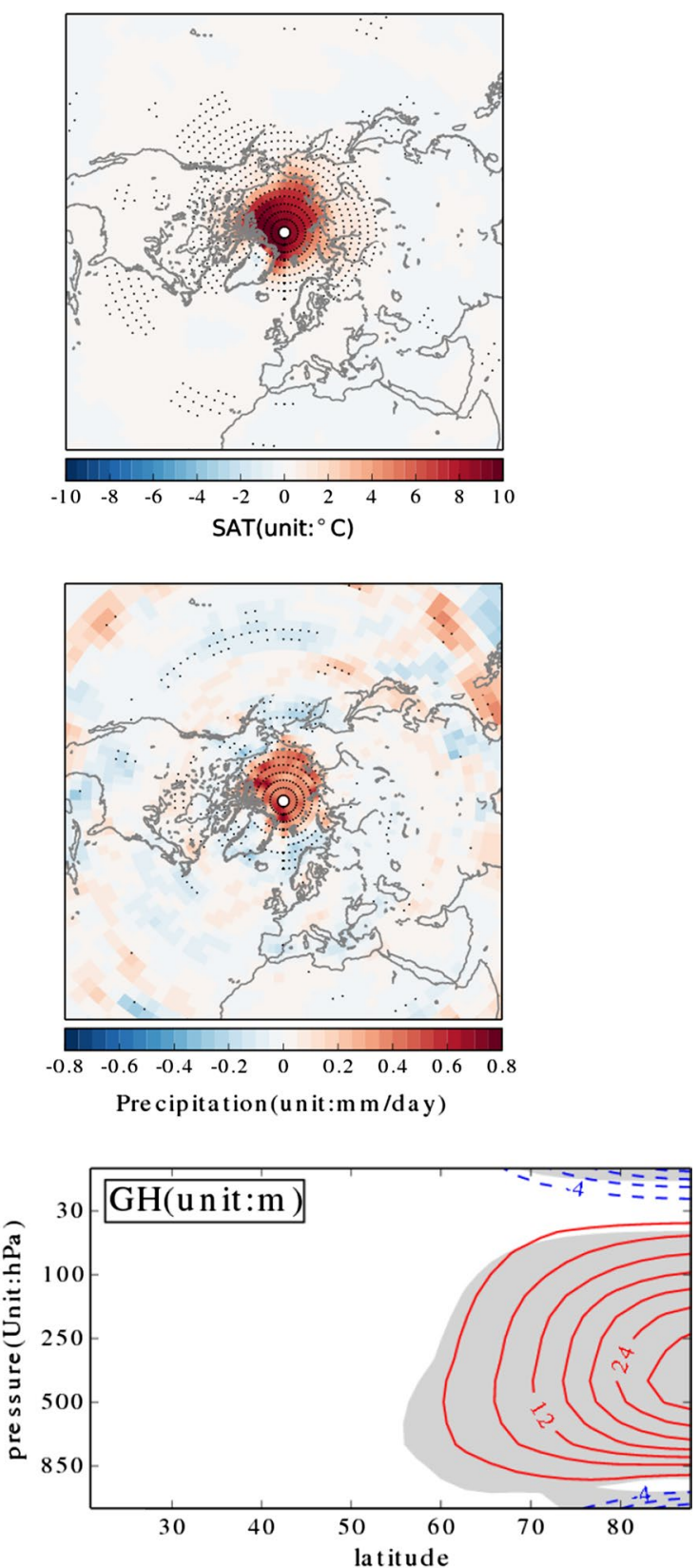

in $\mathbf{a}$ and shaded area in $\mathbf{b}$ present the regions where the responses can pass $95 \%$ significance test. The line interval is 0.5 for temperature and 4 for GH respectively and zero lines are not plotted in $\mathbf{b}$ 
to the climatology) which could be an explanation for the reduction in upward heat flux there as discussed in Screen et al. (2013). The response of the geopotential height (GH) at $500 \mathrm{hPa}$ shows a classical negative AO pattern with positive anomalies over the Arctic and negative anomalies over the northern part of the North Pacific (Fig. 3a). The maximum of the positive GH anomaly center is around $30 \mathrm{~m}$. The warmer near surface atmosphere has the ability to preserve more precipitable water because of the higher saturation humidity. Accordingly, precipitation also increases over the autumn Arctic sea-ice reduction region. The regional mean increase is about $0.2 \mathrm{~mm} /$ day (Fig. 3a).

The significant autumn warming is located at poleward of $60^{\circ} \mathrm{N}$ and up to around $500 \mathrm{hPa}$ from the surface (Fig. 3b). The strongest zonal mean warming appears near the surface and is around $8{ }^{\circ} \mathrm{C}$. The significant positive zonal mean GH anomalies are from the $850 \mathrm{hPa}$ to the lower stratosphere (around $70 \mathrm{hPa}$ ) in autumn (Fig. 3b). The strongest positive GH anomaly is around $30 \mathrm{~m}$ and located at mid-troposphere over the North Pole. Such GH anomalies indicate that the polar vortex gets weaker and a significant negative $\mathrm{AO}$ pattern appears in the troposphere in autumn in response to the autumn sea-ice free Arctic.

(a)

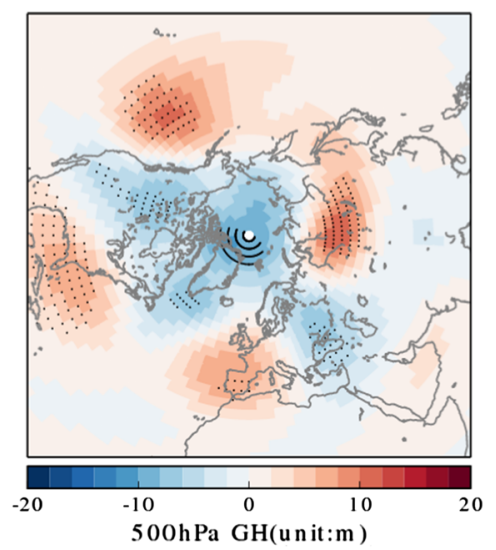

(b)

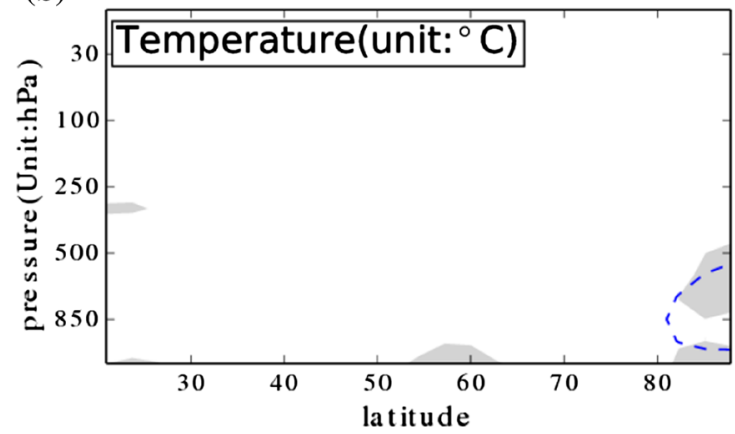

Fig. 4 The simulated Jan-Feb mean a $500 \mathrm{hPa}$ geopotential height (GH) and SAT responses and b zonal mean temperature and GH responses in the SENSICE. The black dots in a and shaded area in
The autumn atmospheric responses can persist into December with much weaker intensity in our simulations (Figure not shown). However, the autumn response patterns disappear in January and February (JF). The JanuaryFebruary (JF) responses show distinct patterns from the autumn responses.

When Arctic sea-ice fully recovers, there is no significant upward heat flux increases over the Arctic Ocean in JF. There are no significant large scale JF precipitation responses found in either the SENS or the SENSICE cases (Figure not shown) so that the precipitation responses in the JF mean will not be discussed any more. The warming over the Arctic Ocean disappears; instead there is a weak but still statistically significant warming over the northern Eurasia continent and the south-east of North America with cooling over the north-west of North America and the east of China in JF (Fig. 4a). When the autumn SAT responses can be mainly attributed to the Arctic heat flux increases, the JF SAT responses are related to the atmospheric circulation changes. As shown in Fig. 4a, the responses of GH at $500 \mathrm{hPa}$ show a wave-train like pattern. The anomalous highs are located at the north-east of the North Pacific, the south-west of the North Atlantic, the north-east of the
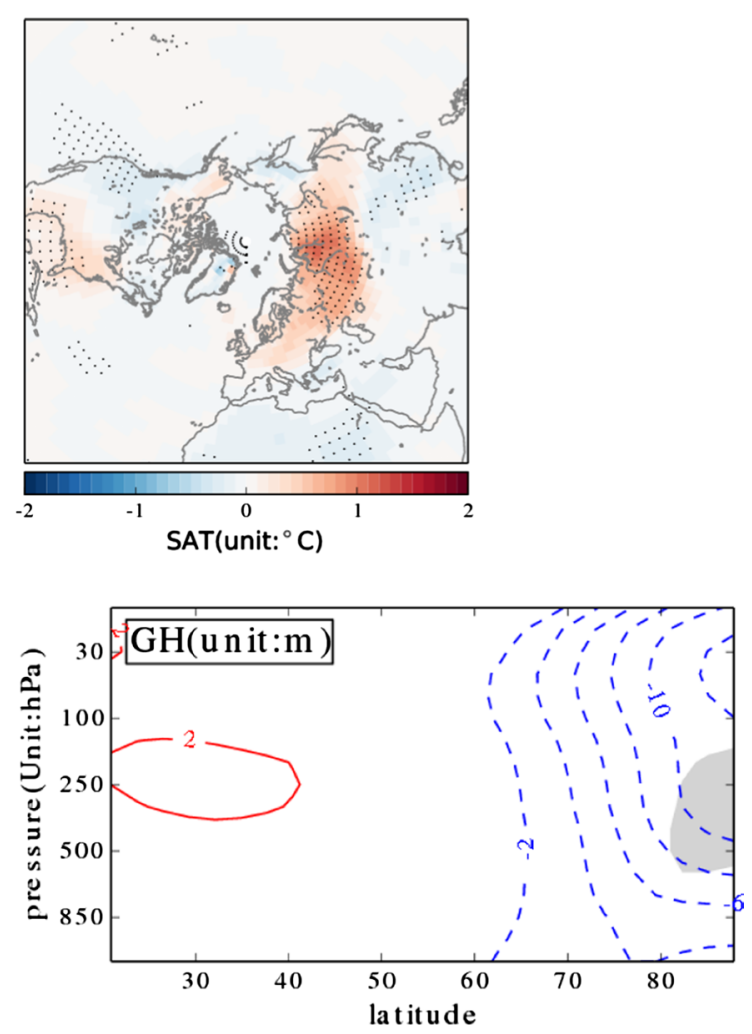

b present the regions where the responses can pass $95 \%$ significance test. The line interval is 0.25 for temperature and 2 for GH respectively and zero lines are not plotted in $\mathbf{b}$ 
North Atlantic and the north of Asia. The anomalous lows are located at the north-west of North America, Greenland, Eastern Europe and the West of Russia. The anomalous low over East Europe and the West of Russia and the anomalous high over the north of the Asia are associated with anomalous northward flow into the northern Eurasia which causes a warming there. The regional mean of the warming over northern Eurasia is $0.69^{\circ} \mathrm{C}$ (only the grids where the responses are significant are chosen for computation).

The JF zonal mean temperature response nearly disappears and there is a weak cooling (below $-0.3{ }^{\circ} \mathrm{C}$ ) in the lower troposphere poleward of $80^{\circ} \mathrm{N}$ as shown in Fig. $4 \mathrm{~b}$.
The zonal mean $500 \mathrm{hPa} \mathrm{GH}$ presents a positive $\mathrm{AO}$ resemblance response in JF but only the response between 500 and 250 hpa poleward of $80^{\circ} \mathrm{N}$ is statistically significant.

\subsection{Responses to the autumn Arctic SIC free and SST changes in the SENS}

In response to the future projected autumn sea-ice free Arctic and the specified SST changes, the autumn surface upward heat fluxes increase over the Arctic Ocean, the Pacific and Atlantic marginal regions (Fig. 5a). The regional mean heat flux increase over the sea-ice reduction (a)
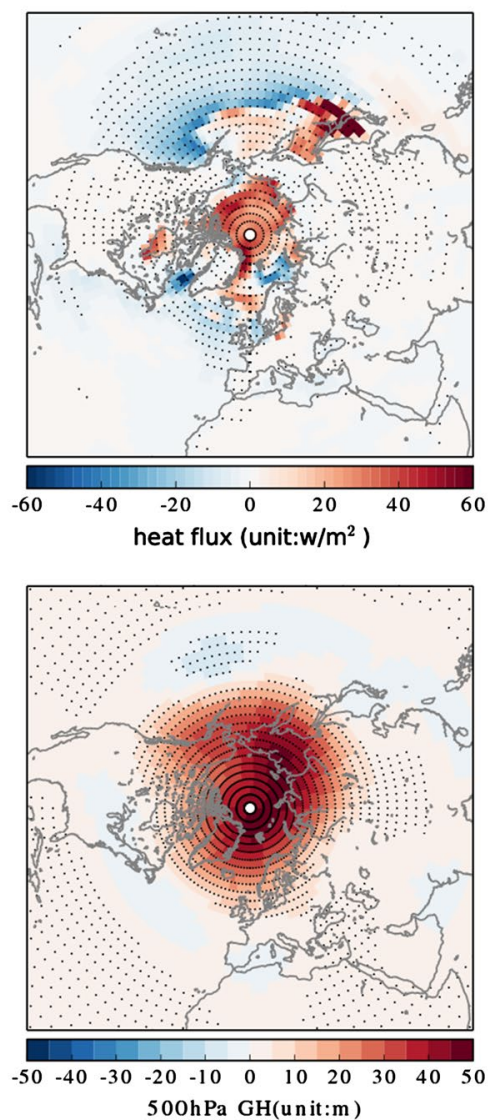

(b)

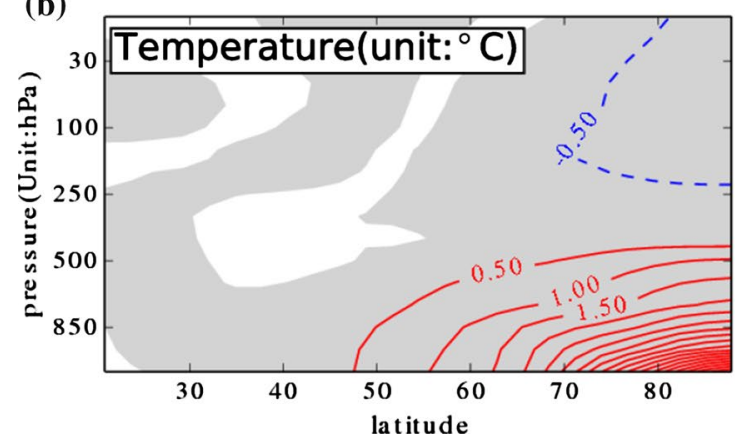

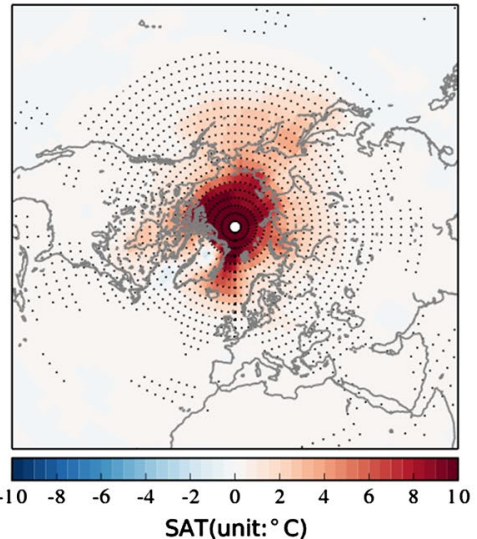
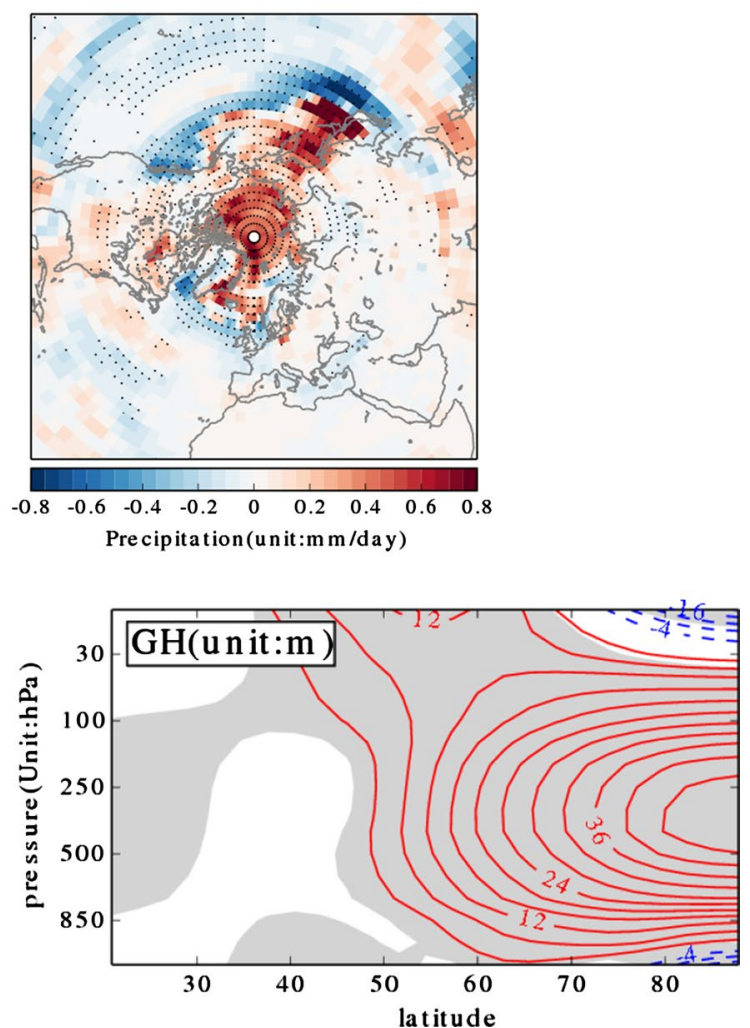

Fig. 5 Same as Fig. 3 except for the responses in the SENS 
region is around $16.8 \mathrm{~W} / \mathrm{m}^{2}, 46 \%$ higher than that in the SENSICE. The regional mean heat flux increase over the Pacific and Atlantic marginal region is around 19.8 and $4.5 \mathrm{~W} / \mathrm{m}^{2}$ respectively. The near surface warming appears over the Arctic Ocean, the Pacific and Atlantic marginal regions (Fig. 5a). The regional mean warming over the seaice reduction/Pacific marginal/Atlantic marginal region is around $6.6 / 2.3 / 1.7^{\circ} \mathrm{C}$. The warming over the sea-ice reduction region is about $43 \%$ higher than that in SENSICE. The response of the geopotential height $(\mathrm{GH})$ at $500 \mathrm{hPa}$ also shows a classical negative AO pattern (Fig. 5a). The peak of the positive $\mathrm{GH}$ anomaly is around $45 \mathrm{~m}$, stronger than that in the SENS. The precipitation increases not only over the autumn Arctic sea-ice reduction region but also over the Pacific and Atlantic marginal regions (Fig. 5a). The regional mean precipitation increase is about $0.3 \mathrm{~mm} /$ day over the sea-ice reduction region, $50 \%$ higher than that in the SENSICE and about $0.4 / 0.15 \mathrm{~mm} /$ day over the Pacific/ Atlantic marginal region.

The autumn zonal mean temperature and GH responses also show similar patterns in the SENS as in the SENSICE (Fig. 5b). But the intensity of the responses is stronger in the SENS than in the SENSICE. The strongest zonal mean warming is around $9.5{ }^{\circ} \mathrm{C}$ near the surface. The positive $\mathrm{GH}$ anomaly exceeds $44 \mathrm{~m}$ between 250 and $500 \mathrm{hPa}$ poleward of $80^{\circ} \mathrm{N}$.

(a)
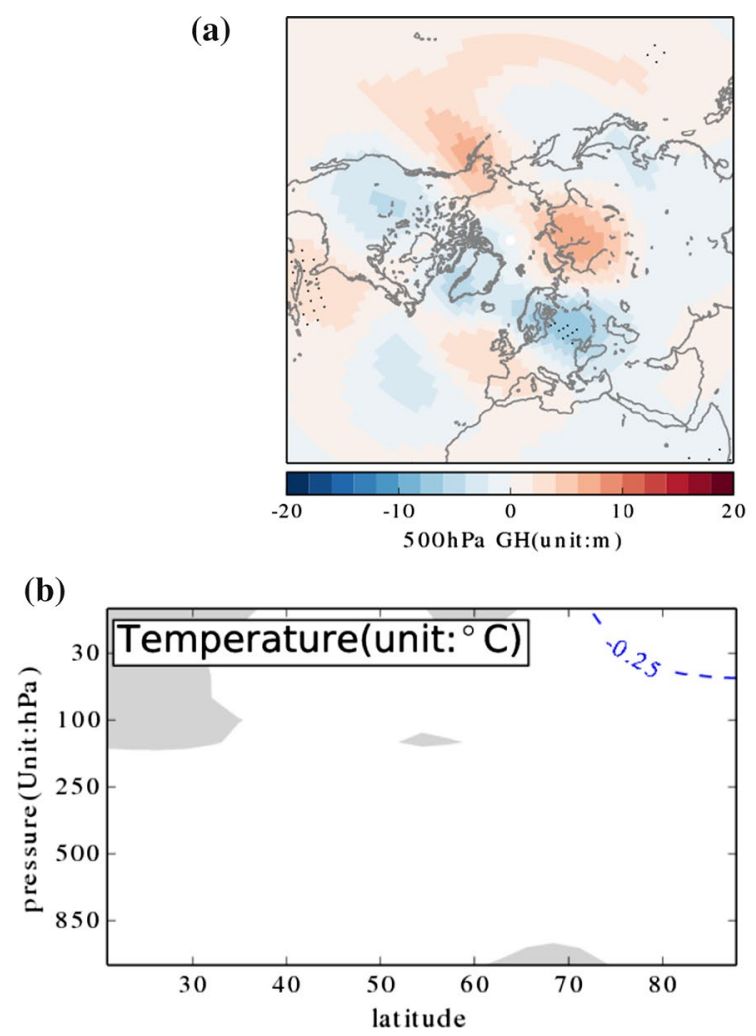

The JF $500 \mathrm{hPa}$ GH and SAT responses show a similar pattern in the SENS as in the SENSICE. But the regions where the responses are statistically significant are smaller in the SENS than in the SENSICE. Although the anomalous highs located at the north-east of North Pacific, the south-west of North Atlantic, the north-east of North Atlantic and the north of Asia and the anomalous lows located at the north-west of North America, Greenland, Eastern Europe and the West of Russia are all shown in Fig. 6a, only the low over Eastern Europe and the West of Russia and the high over the south-west of North Atlantic are statistically significant. The SAT changes over the North America are not statistically significant anymore. The warming over northern Eurasia is still statistically significant. The regional mean of the warming over northern Eurasia is $0.62{ }^{\circ} \mathrm{C}$ in the SENS, $0.07{ }^{\circ} \mathrm{C}$ weaker than the warming in the SENSICE.

The vertical structure of the JF zonal mean temperature and GH responses in the SENS (Fig. 6b) is different from those shown in the SENSICE. There are no significant tropospheric responses in the SENS. Instead the zonal mean GH responses show an intensified polar vortex in the stratosphere with the statistically significant responses located in mid-latitudes.

The similar wave energy propagation during the November-December (ND) has been found in both the SENSICE
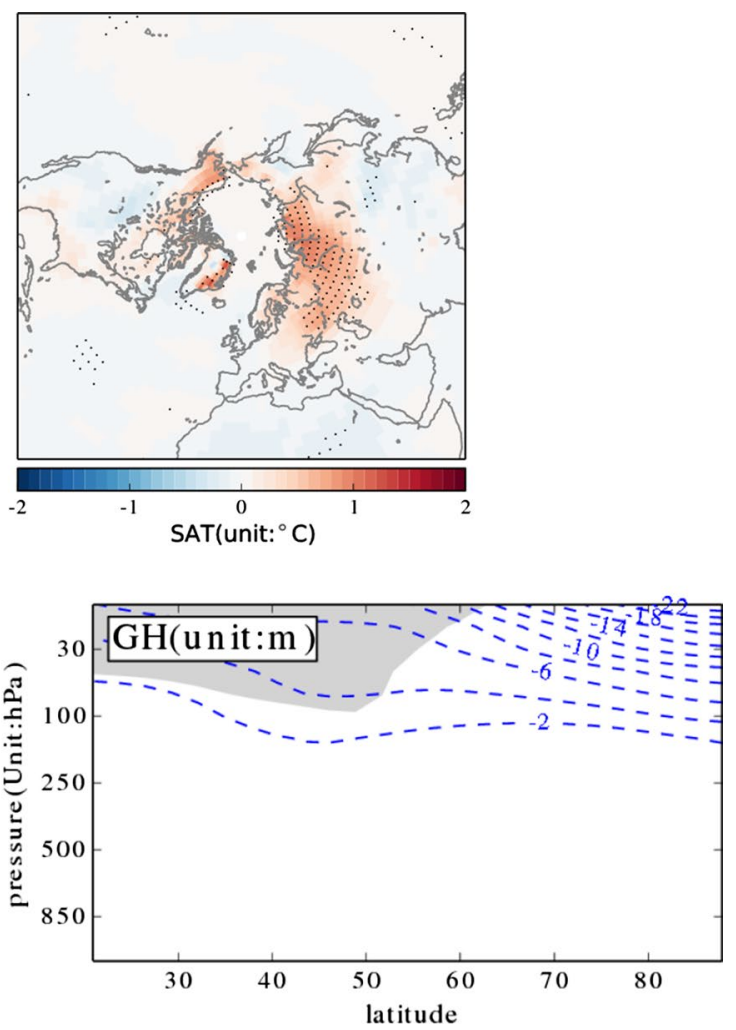

Fig. 6 Same as Fig. 4 except for the responses in the SENS 
and the SENS which might be a possible reason to cause the similar JF atmospheric responses. The wave activity flux is computed using the method defined in Takaya and Nakamura (2001). It's clearly shown that the anomalous wave energy comes from the Arctic Ocean and the northern Pacific, and propagates to the sub-Arctic region (Fig. 7). The divergent/convergent region of the wave energy flux indicates where the wave emits/decays (or is absorbed). The new wave can possibly develop where the wave energy flux is convergent (Takaya and Nakamura 2001). In Fig. 7 the convergence of the wave energy in the ND mean is located near Alaska, Hudson Bay, Greenland, the north-east of the North Atlantic, Eastern Europe and the northern Asia where indeed the anomalous lows or highs develop in JF.

In order to find out why the JF responses are weaker in the SENS than in the SENSICE, a multiple linear regression has been used to check if the responses in JF caused by heat flux changes over the autumn Arctic Ocean, Atlantic marginal and Pacific marginal regions are the same or different. The partially regressed $500 \mathrm{hPa} \mathrm{JF}$ GH responses on the regional mean of the autumn heat flux changes over the Pacific and Atlantic marginal regions are shown in Fig. 8. Comparing Figs. $8 \mathrm{a}$ and $4 \mathrm{a}$, it can be found that the pattern associated with the autumn heat flux increase over the Pacific marginal regions is basically opposite of the pattern caused by the autumn central Arctic Ocean sea-ice reduction across most of the northern hemisphere. The autumn regional mean heat flux increase over the Atlantic marginal region is accompanied with a negative AO (NAO) pattern in JF. The variation associated with the autumn heat flux over the Atlantic marginal region is much weaker than that related to the Pacific marginal region. The reduction of the response significance in the SENS compared with the SENSICE might be attributed to the inclusion of the autumn SST increase in the Pacific marginal region which causes an increase in the local upward heat flux.

The differences of the JF zonal mean responses in the SENS and SENSICE might also be related to the inclusion of the autumn SST increase in the Pacific marginal region. As discussed, the higher autumn SST in the North Pacific marginal region might reduce the significance of the JF responses in the troposphere; on the other hand, several previous studies discussed that the weakened JF Aleutian low associated with the higher autumn SST in the North Pacific marginal region as shown in Fig. 8a can inhibit the upward planetary wave propagation into the stratosphere which is accompanied by an intensification of the polar vortex over the North America side (Nishii et al. 2010; Hurwitz et al. 2012). The partially regressed $50 \mathrm{hPa}$ JF GH responses on the regional mean of the autumn heat flux changes over the Pacific marginal regions (Fig. 8b) are consistent with the conclusion of previous studies. The autumn heat flux over the Atlantic marginal region might contribute to an intensification of the polar vortex at $50 \mathrm{hPa}$ over (a) SENSICE

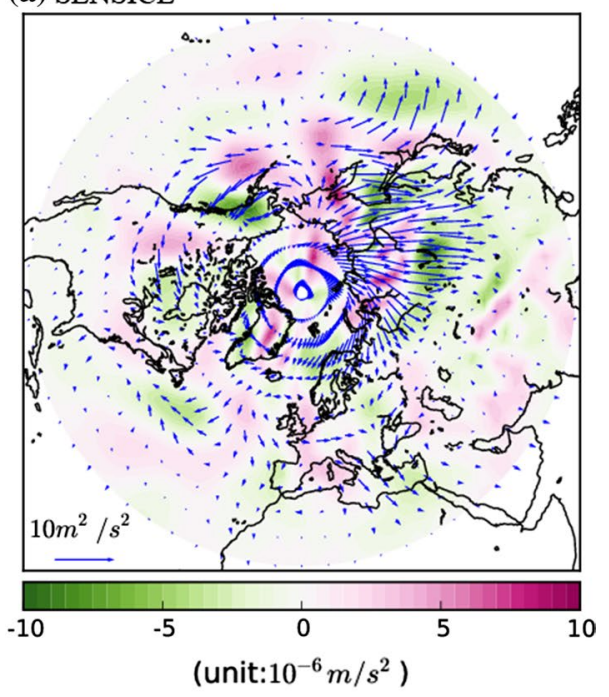

(b) SENS

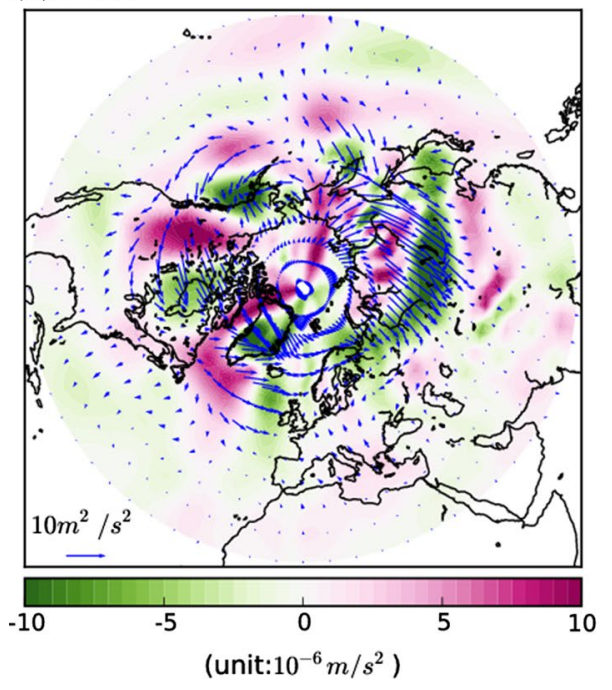

Fig. 7 The simulated November-December mean 500 hPa horizontal wave energy flux anomalies (vectors) and the divergence of the anomalous wave flux (color shaded) in a) the SENSICE and b) the SENS

the Greenland-Icelandic-Norwegian Seas but the variation associated with the autumn heat flux over the Atlantic marginal region is much weaker than that related to the Pacific marginal region. The simulated $50 \mathrm{hPa} \mathrm{GH}$ responses in the SENS (Fig. 8c) do show a similar pattern as the regressed pattern on the autumn heat flux changes over the Pacific marginal regions while the responses in the SENSICE show a distinct pattern.

\subsection{Detectability of the responses}

Figure 9 shows the ratios of the ensemble mean to the SD of the 300 ensemble responses in autumn and JF. The ratios 
Fig. 8 The partially regressed Jan-Feb mean GH responses at a $500 \mathrm{hPa}$ and $\mathbf{b} 50 \mathrm{hPa}$ on the regional mean of the autumn heat flux increases over the Pacific and the Atlantic marginal regions, and c simulated Jan-Feb mean $50 \mathrm{hPa}$ geopotential height $(\mathrm{GH})$ responses in the SENS and SENSICE. The black dots in c) present the region where the responses can pass $95 \%$ significance test. Unit: $m$ (a) Regressed $500 \mathrm{hPa} \mathrm{GH}$
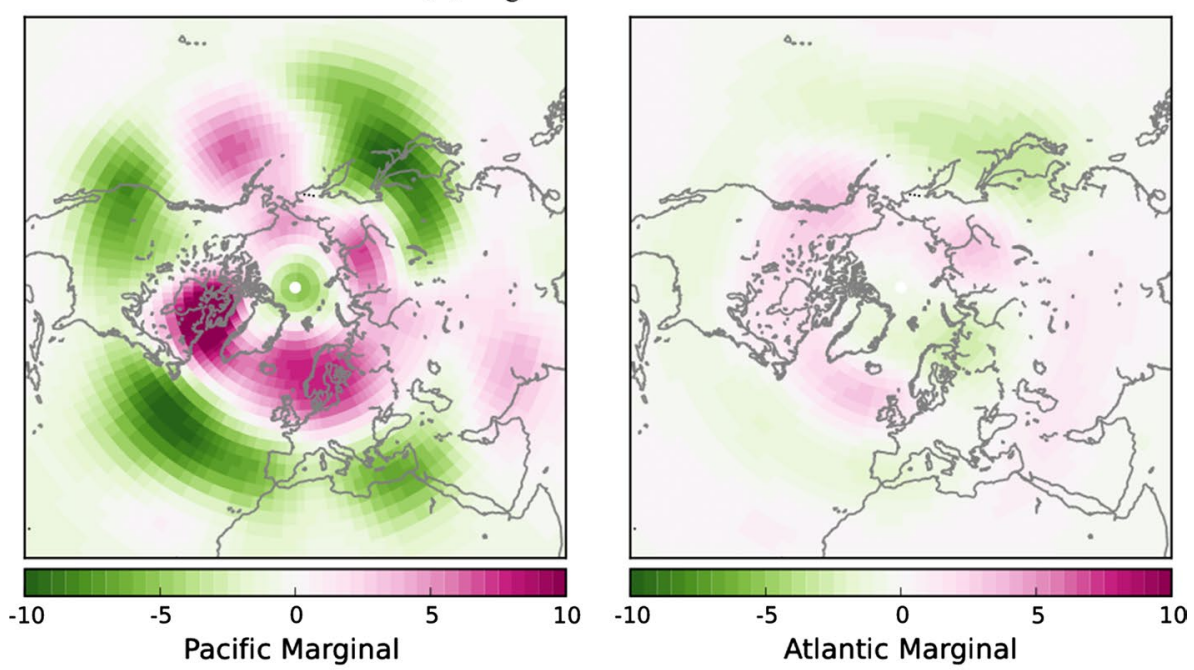

(b) Regressed 50hPa GH
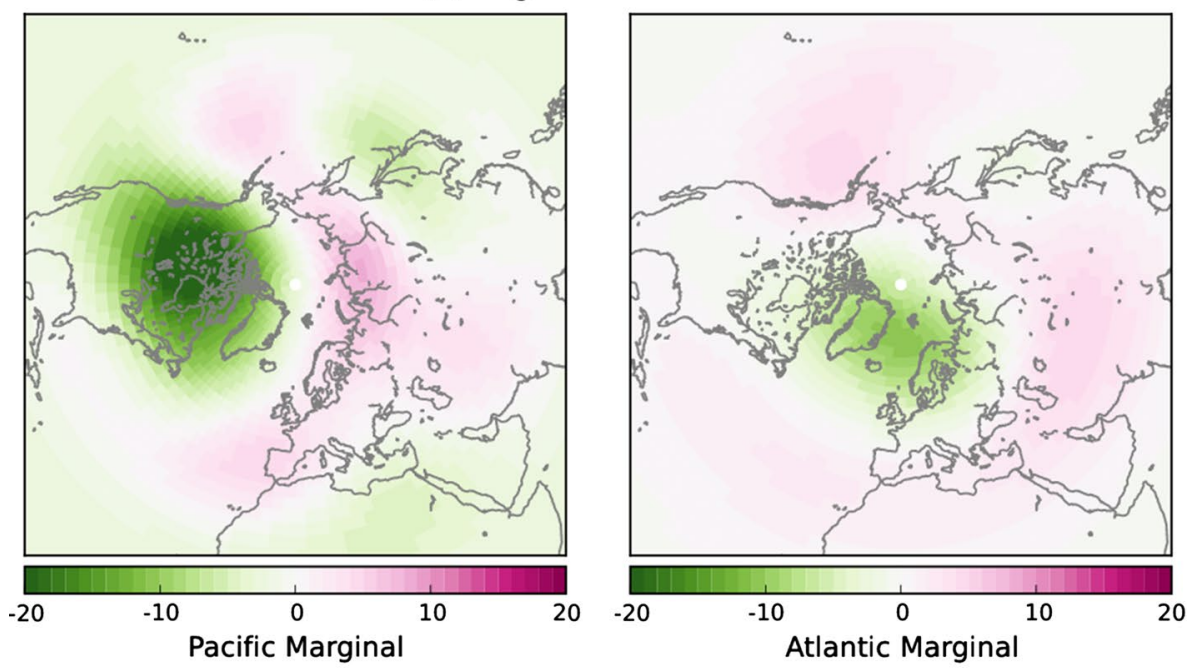

(c) $50 \mathrm{hPa} \mathrm{GH}$ responses
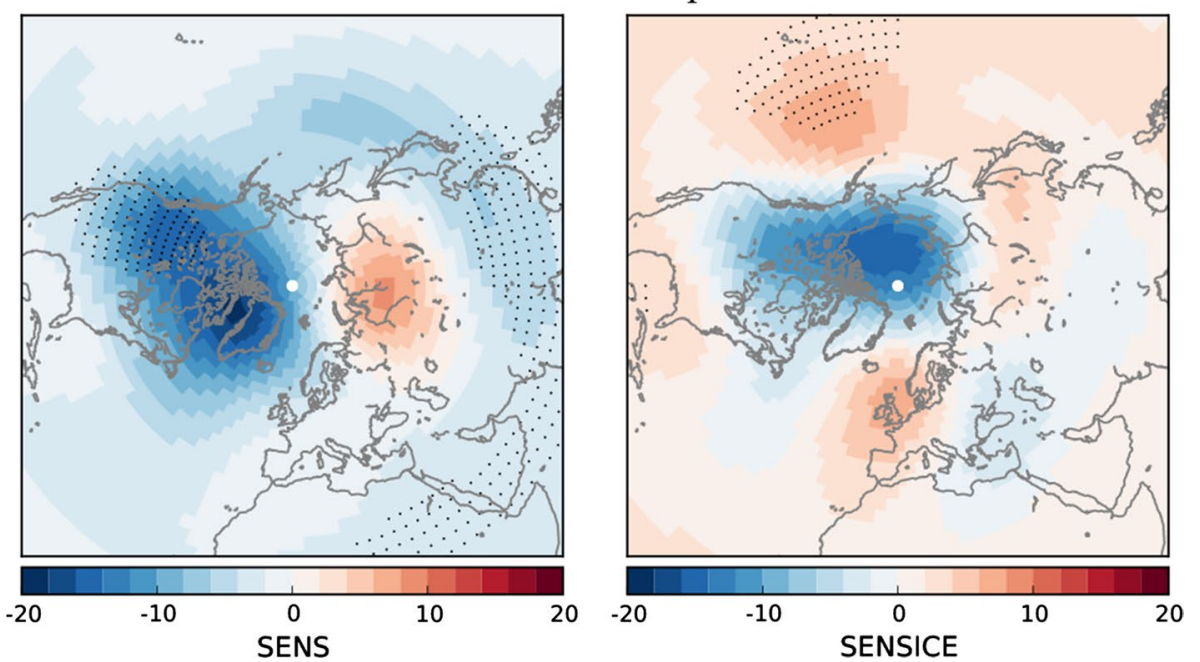

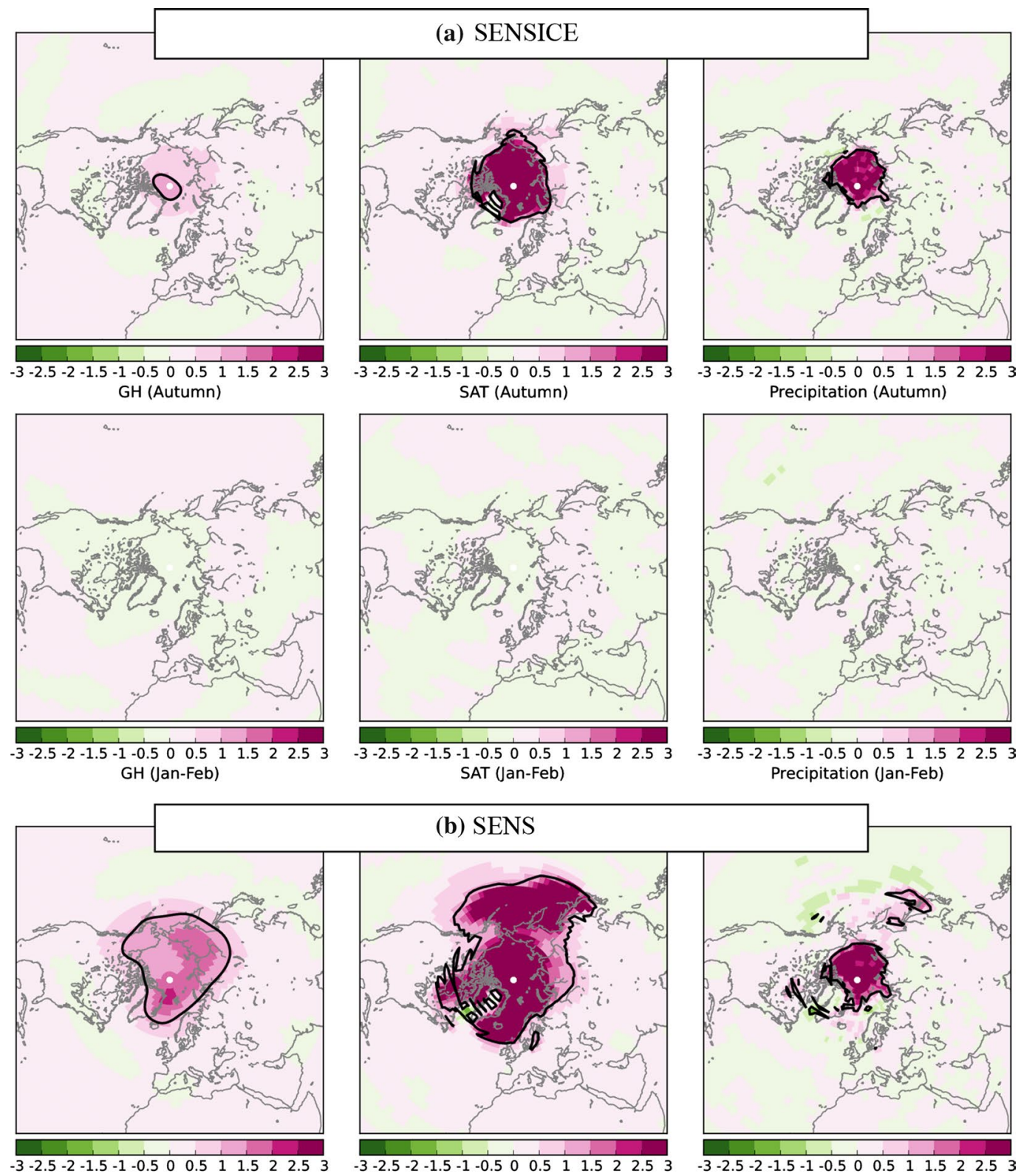

$\mathrm{GH}$ (Autumn)
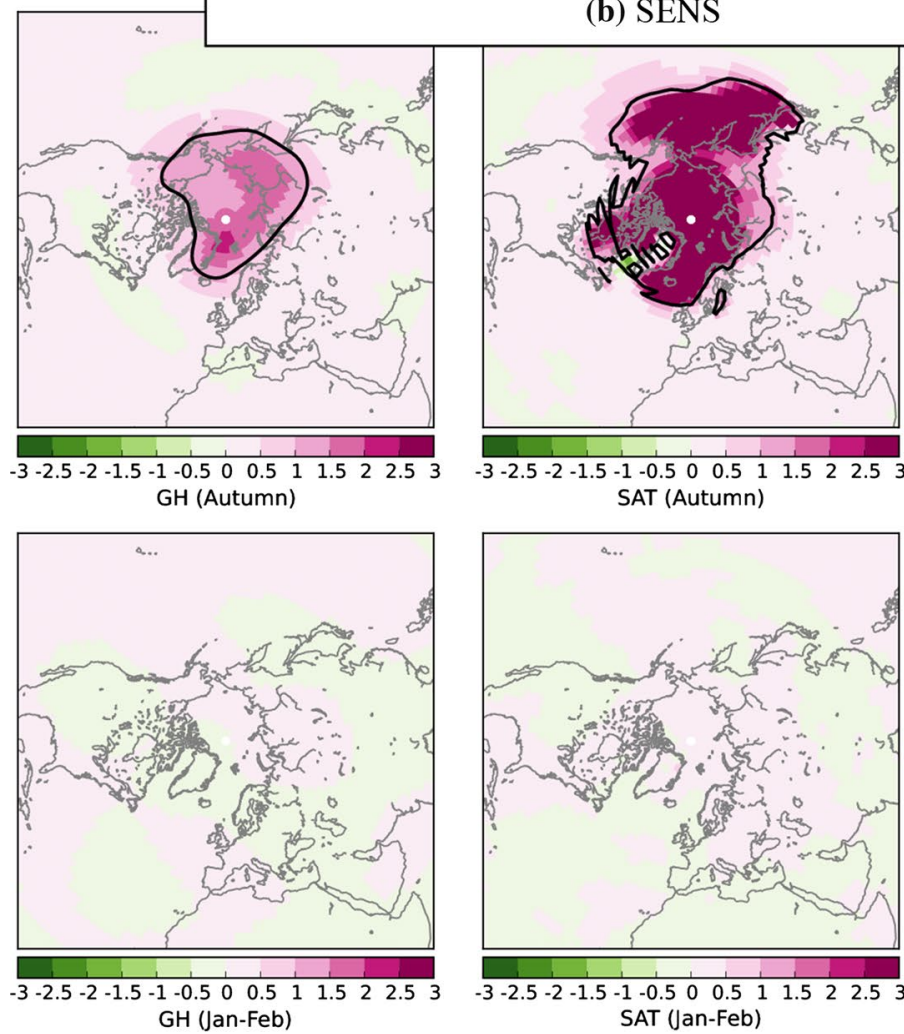

SAT (Autumn)
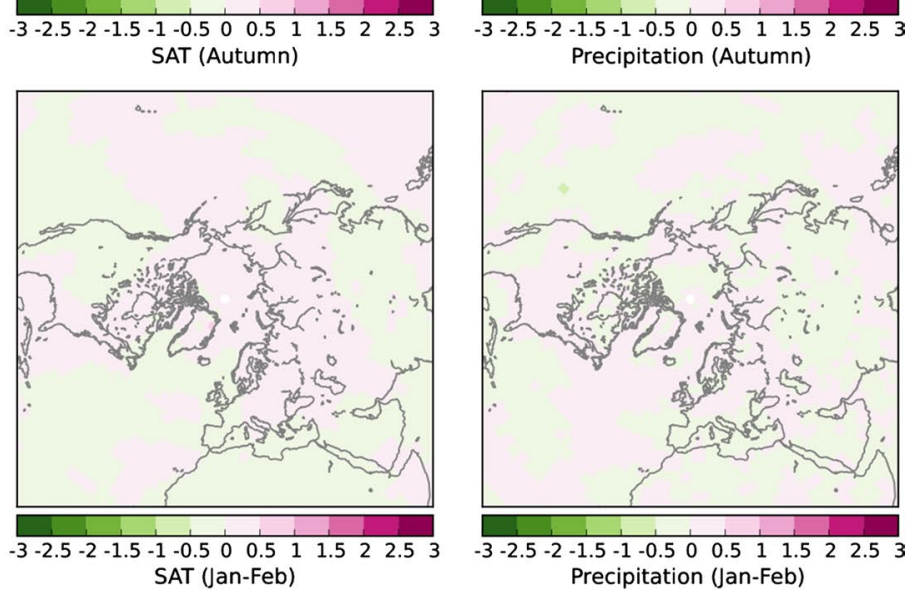

Precipitation (Autumn)

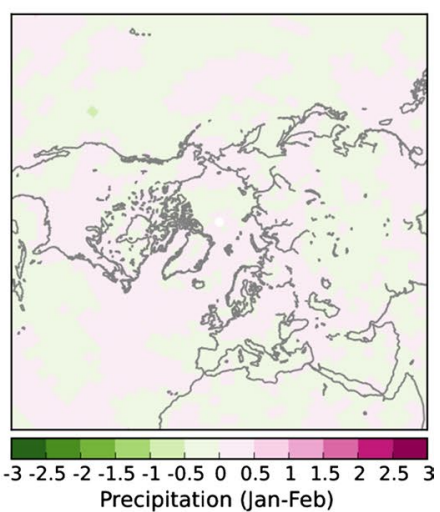

Fig. 9 Ratios of the mean to the standard deviation of the autumn and Jan-Feb mean $500 \mathrm{hPa} \mathrm{GH,} \mathrm{SAT} \mathrm{and} \mathrm{precipitation} \mathrm{responses} \mathrm{among} \mathrm{the}$ 300 ensembles in $\mathbf{a}$ the SENSICE and $\mathbf{b}$ the SENS. The black lines mark where absolute value of the ratios is 1 


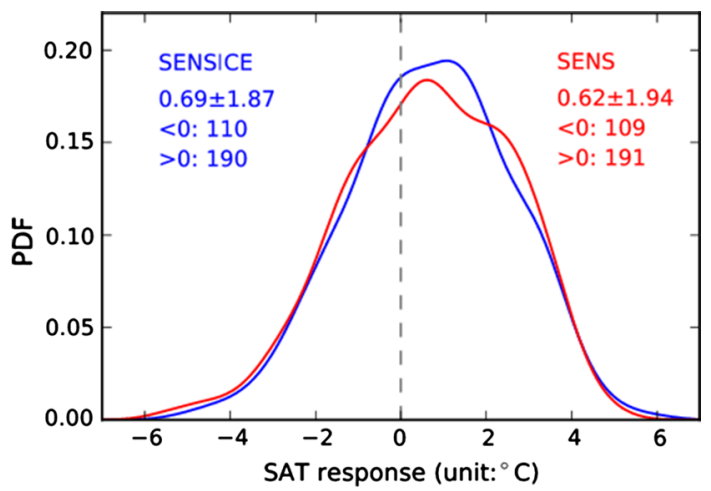

Fig. 10 The PDFs of the regional mean JF SAT warming over the northern Eurasia. Only the grids where the responses pass the significance test as marked in Figs. 4a and 6a by black dots are chosen for the computation of regional mean. The numbers show the mean \pm the standard deviations of the responses and how many ensembles present the positive $(>0)$ or negative $(<0)$ responses. The results in the SENSICE and the SENS are shown in blue and red color respectively can be treated as the estimation of the mean response to the spread caused by AIV. The autumn $500 \mathrm{hPa} \mathrm{GH}$ responses are comparable $(0.5<$ ratios $<1)$ to the standard deviations over the Arctic Ocean and exceed the AIV on the north of Greenland in the SENSICE. In the SENS, the autumn $500 \mathrm{hPa} \mathrm{GH}$ responses can exceed the standard deviations (ratios > 1) over the Arctic Ocean, northern Asia, Alaska and the north of the GIN seas. The ratios of the autumn SAT responses over the Arctic Oceans can exceed 3 in both the SENSICE and the SENS which indicates high detectability. In the SENS, the ratios of the autumn SAT responses can also exceed 3 over the northern North Pacific. The detectability of the precipitation responses is between that for the SAT and SLP responses: The autumn precipitation changes over the central Arctic Ocean are easily detectable (the absolute ratios exceed 3) in both the SENSICE and the SENS; In the SENS, the ratios can also exceed 1 in the sea of Okhotsk and the north of the sea of Japan.
Fig. 11 Ratios of the SAT responses in the SENSICE and the SENS to the differences between the ProjBCM (last 20 years mean) and the ContBCM (100 year mean) in autumn and JF. The black dots present the regions where the responses can pass $95 \%$ significance test
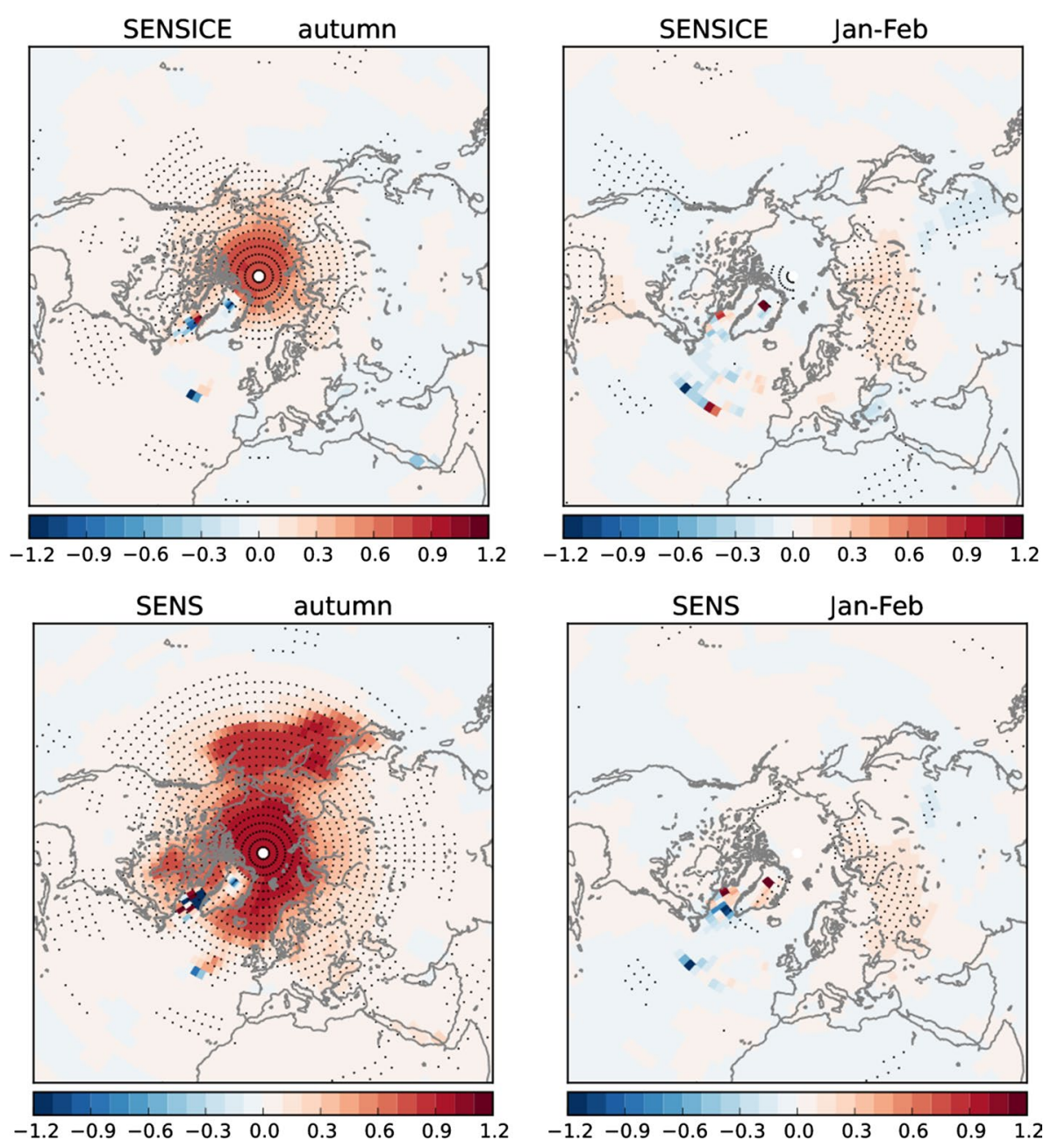
In JF, the ratios of the $500 \mathrm{hPa} \mathrm{GH}$, SAT and precipitation responses are generally much weaker than the internal variability (absolute ratios $<0.5$ ). Therefore, the simulated $\mathrm{JF}$ atmosphere responses are not easily detectable due to the AIV.

The surface warming located over northern Eurasia is one of the most prominent responses in JF and is chosen for further comparison with the AIV. The PDFs of the regional mean SAT warming are shown in Fig. 10. In a total of 300 members, 190 (191)/110 (109) members present warmer/colder SAT responses in the SENSICE (SENS). The ensemble mean of the regional mean SAT response is $0.69{ }^{\circ} \mathrm{C}\left(0.62{ }^{\circ} \mathrm{C}\right)$ and the standard deviation is $1.87{ }^{\circ} \mathrm{C}$ $\left(1.94{ }^{\circ} \mathrm{C}\right)$ in the SENSICE (SENS).The standard deviation is about 3 times greater than the mean response for the regional mean SAT. Although the autumn sea-ice free Arctic (and the associated SST changes) can potentially drive a northern Eurasia warming in JF, such responses are difficult to detect due to strong internal variability.

The low detectability of the JF responses motivates us to consider that to what extent the climate responses to the increasing $\mathrm{CO}_{2}$ concentration in the future can be attributed to the sea-ice feedback. Figure 11 shows the ratios of the SAT responses in the SENSICE and the SENS to the differences between the ProjBCM (last 20 years mean) and the ContBCM (100 year mean). Generally, the autumn SAT responses to the increasing $\mathrm{CO}_{2}$ concentration can be fully explained by the sea-ice and SSTs feedback in the Arctic and in the North Pacific where the ratios are close to 1 in the SENS. The sole sea-ice feedback in the SENSICE can explain around $60-80 \%$ of the warming over the Arctic Oceans in the ProjBCM. In JF, there is also a northern Eurasia warming in the ProjBCM compared with the ContBCM. The sea-ice feedback in the SENSICE (sea-ice and SSTs feedback in the SENS) can explain around $30 \%$ of the warming.

\section{Discussions and conclusions}

We have used a large ensemble (300) of AGCM simulations to investigate the atmospheric response to the projected autumn Arctic sea-ice disappearance. Three experiments have been performed, the CONT forced by the model simulated present-day Arctic SIC and SST, the SENSICE forced by the projected autumn Arctic SIC free and present-day SSTs and the SENS forced by the projected autumn Arctic SIC free and projected SSTs. Our simulations indicate that:

1. The autumn sea-ice free Arctic can cause significant autumn near-surface warming and precipitation increases over the sea-ice reduction region. A significant negative $\mathrm{AO}$ response appears in the troposphere in autumn which was also reported by previous studies (e.g. Screen et al. 2013). The intensity of the regional mean heat flux, SAT and precipitation responses over the sea-ice reduction region increases 46,43 and $50 \%$ respectively when future projected SSTs are specified in the SENS, which is consistent with the prescribed boundary setting: the regional mean ST increase over the sea-ice reduction region is $48 \%$ higher in the SENS than in the SENSICE.

2. The atmospheric response pattern in autumn does not persist into JF in our simulation. There is no negative AO resembling pattern in JF. Instead, a wave train like pattern appears at $500 \mathrm{hPa}$ GH both in the SENS and in the SENSICE. Such wave train pattern is related to the slowly downstream propagation of the planetary wave perturbations caused by the autumn sea-ice free Arctic. The anomalous low located over Eastern Europe and the west of Russia and the high located over northern Asia are associated with the anomalous northward flow into northern Eurasia, which results in a warming anomaly there.

3. The comparison of the atmosphere responses with the AIV shows that the response of SAT and precipitation are much greater than the AIV over the Arctic during the autumn so that can be easily detected. The response of $500 \mathrm{hPa} \mathrm{GH}$ is comparable to the AIV in autumn. We note none of the JF responses exceed the AIV.

Here, our work focuses on the atmospheric responses to the projected autumn sea-ice free Arctic with AGCM simulations. The sea-ice reductions during different seasons could result in different simulated winter responses. As stated in Tang et al. (2013), the winter atmospheric circulation change and cold extremes are associated with both autumn and winter sea-ice reduction but through different mechanisms. Thus, the improper setting of the winter sea-ice reduction in the model might have an impact on the results of the winter atmosphere circulation changes and the related weather events in response to the autumn seaice retreat. The JF responses in our simulation are different from previous studies (Deser et al. 2010; Liu et al. 2012; Semmler et al. 2012) which reported simulated negative winter AO. One of the possible reasons is that the winter sea-ice variations were evolved into the model simulations in those studies.

The lagged winter atmosphere responses might be sensitive to the selection of the autumn sea-ice reduction regions. The different location and extent of the sea-ice reduction could result in different atmospheric response patterns (Peings and Magnusdottir 2014). As discussed in this study, the heat flux changes over the central Arctic, the Pacific and Atlantic marginal regions are associated with different JF response patterns. 
It is also possible that the JF responses to the future projected sea-ice free Arctic reported here are different from the responses to the present Arctic sea-ice reductions. The autumn Arctic sea-ice reductions during the several recent decades are generally located at the marginal ice zones with the most intensive reductions located at the Beaufort Sea and the East Siberia Sea (Screen et al. 2013). Some previous studies reported a statistical relation between the winter negative NAO and the recent sea-ice reductions (Wu and Zhang 2010; Jaiser et al. 2012). The pattern reported by those studies resembles the pattern associated with the autumn heat flux changes over the Pacific and Atlantic marginal regions presented in Fig. 8. But these patterns can be offset by the response to the autumn central Arctic sea-ice reduction so that the JF GH presents a distinctly different response in our simulations.

The ocean-atmosphere feedback out of the Arctic is disregarded in our simulations. The SSTs outside of the sea-ice loss region could change in a free coupled oceanatmosphere system. It is possible that such SST changes could have an impact on the autumn-winter atmosphere. The possible indirect impact has not been taken into consideration in our AGCM simulations when the SSTs outside of the Arctic are set as the reference climatology both in the CONT and the SENS/SENSICE. The role of the oceanatmosphere feedback in the winter atmosphere responses to autumn sea-ice retreat will be analyzed and discussed in a future study.

Acknowledgments This work has been supported by the Research Council of Norway through the BlueArc project (207650/E10) and the European Union 7th Framework Programme (FP7 2007-2013) through the NACLIM project (308299). This work also contributes to the National Natural Sciences Foundation of China supported projects (41375083, 41210007, 41176169), and the joint NorwegianRussian project NORRUS-CLIMARC (225032). This research is also funded by the NOAA Climate Observations and Monitoring Program (NA14OAR4310216). The views expressed herein are those of the author(s) and do not necessarily reflect the views of NOAA.

Open Access This article is distributed under the terms of the Creative Commons Attribution 4.0 International License (http://creativecommons.org/licenses/by/4.0/), which permits unrestricted use, distribution, and reproduction in any medium, provided you give appropriate credit to the original author(s) and the source, provide a link to the Creative Commons license, and indicate if changes were made.

\section{References}

Bader J, Mesquita MDS, Hodges KI, Keenlyside N, Østerhus S, Miles M (2011) A review on Northern Hemisphere sea-ice, storminess and the North Atlantic Oscillation: observations and projected changes. Atmos Res 101(4):809-834

Bleck R, Rooth C, Hu D, Smith LT (1992) Salinity-driven thermocline transients in a wind- and thermohaline-forced isopycnic coordinate model of the North Atlantic. J Phys Oceanogr. doi:10.1175/1520-0485(1992)022<1486:SDTTIA >2.0.CO;2

Blüthgen J, Gerdes R, Werner M (2012) Atmospheric response to the extreme Arctic sea ice conditions in 2007. Geophys Res Lett 39(2):L2707. doi:10.1029/2011GL050486

Comiso JC, Parkinson CL, Gersten R, Stock L (2008) Accelerated decline in the Arctic sea ice cover. Geophys Res Lett 35(1):L1703. doi:10.1029/2007GL031972

Dee DP, Uppala SM, Simmons AJ, Berrisford P, Poli P, Kobayashi S et al (2011) The ERA-Interim reanalysis: configuration and performance of the data assimilation system. Q J R Meteorol Soc 137(656):553-597. doi:10.1002/qj.828

Déqué M, Dreveton C, Braun A, Cariolle D (1994) The ARPEGE/ IFS atmosphere model: a contribution to the French community climate modelling. Clim Dyn 10(4):249-266. doi:10.1007/ BF00208992

Deser C, Tomas R, Alexander M, Lawrence D (2010) The seasonal atmospheric response to projected Arctic sea ice loss in the late twenty-first century. J Clim 23(2):333-351. doi:10.1175/2009J CLI3053.1

Francis JA, Chan W, Leathers DJ, Miller JR, Veron DE (2009) Winter Northern Hemisphere weather patterns remember summer Arctic sea-ice extent. Geophys Res Lett 36(7):L7503. doi:10.1029/200 9GL037274

Honda M, Inoue J, Yamane S (2009) Influence of low Arctic sea-ice minima on anomalously cold Eurasian winters. Geophys Res Lett 36(8):L8707. doi:10.1029/2008GL037079

Hurwitz MM, Newman PA, Garfinkel CI (2012) On the influence of North Pacific sea surface temperature on the Arctic winter climate. J Geophys Res: Atmos 117(D19):D19110. doi:10.1029/2 012JD017819

Jaiser R, Dethloff K, Handorf D, Rinke A, Cohen J (2012) Impact of sea ice cover changes on the Northern Hemisphere atmospheric winter circulation. Tellus A. doi:10.3402/tellusa. v64i0.11595

Johannessen OM, Bengtsson L, Miles MW, Kuzmina SI, Semenov VA, Alekseev GV et al (2004) Arctic climate change: observed and modelled temperature and sea-ice variability. Tellus A 56(4):328-341. doi:10.1111/j.1600-0870.2004.00060.x

Kumar A, Perlwitz J, Eischeid J, Quan X, Xu T, Zhang T et al (2010) Contribution of sea ice loss to Arctic amplification. Geophys Res Lett 37(21):L21701. doi:10.1029/2010GL045022

Li F, Wang H (2013a) Spring surface cooling trend along the East Asian coast after the late 1990s. Chin Sci Bull 58(31):38473851. doi:10.1007/s11434-013-5853-8

Li F, Wang H (2013b) Autumn sea ice cover, winter Northern Hemisphere annular mode, and winter precipitation in Eurasia. J Clim 26(11):3968-3981. doi:10.1175/JCLI-D-12-00380.1

Liu J, Curry JA, Wang H, Song M, Horton RM (2012) Impact of declining Arctic sea ice on winter snowfall. Proc Natl Acad Sci USA 109(11):4074-4079. doi:10.1073/pnas.1114910109

Liu J, Song M, Horton RM, Hu Y (2013) Reducing spread in climate model projections of a September ice-free Arctic. Proc Natl Acad Sci USA 110(31):12571-12576. doi:10.1073/pnas.1219716110

Na L, Jiping L, Zhanhai Z, Hongxia C, Mirong S (2012) Is extreme Arctic sea ice anomaly in 2007 a key contributor to severe January 2008 snowstorm in China? Int J Climatol 32(13):2081-2087. doi: $10.1002 /$ joc. 2400

Nishii K, Nakamura H, Orsolini YJ (2010) Cooling of the wintertime Arctic stratosphere induced by the western Pacific teleconnection pattern. Geophys Res Lett 37(13):L13805. doi:10.1029/20 10GL043551

Otterå OH, Bentsen M, Bethke I, Kvamstø NG (2009) Simulated preindustrial climate in Bergen Climate Model (version 2): model description and large-scale circulation features. Geosci Model Dev 2(1):197-212. doi:10.5194/gmd-2-197-2009 
Overland JE, Wang M (2013) When will the summer arctic be nearly sea ice free? Geophys Res Lett 40(10):2097-2101. doi:10.1002/ grl.50316

Peings Y, Magnusdottir G (2014) Response of the wintertime Northern Hemisphere atmospheric circulation to current and projected Arctic sea ice decline: a numerical study with CAM5. J Clim 27(1):244-264. doi:10.1175/JCLI-D-13-00272.1

Perovich DK, Richter-Menge JA, Jones KF, Light B (2008) Sunlight, water, and ice: extreme Arctic sea ice melt during the summer of 2007. Geophys Res Lett 35(11):L11501. doi:10.1029/200 $8 \mathrm{GL} 034007$

Screen JA, Simmonds I, Deser C, Tomas R (2013) The atmospheric response to three decades of observed Arctic sea ice loss. J Clim 26(4):1230-1248. doi:10.1175/JCLI-D-12-00063.1

Screen JA, Deser C, Simmonds I, Tomas R (2014) Atmospheric impacts of Arctic sea-ice loss, 1979-2009: separating forced change from atmospheric internal variability. Clim Dyn 43(12):333-344. doi:10.1007/s00382-013-1830-9

Semmler T, McGrath R, Wang S (2012) The impact of Arctic sea ice on the Arctic energy budget and on the climate of the Northern mid-latitudes. Clim Dyn 39(11):2675-2694. doi:10.1007/ s00382-012-1353-9

Suo L, Otterå OH, Bentsen M, Gao Y, Johannessen OM (2013) External forcing of the early 20th century Arctic warming. Tellus A 65:20578. doi:10.3402/tellusa.v65i0.20578

Takaya K, Nakamura H (2001) A formulation of a phase-independent wave-activity flux for stationary and migratory quasigeostrophic eddies on a zonally varying basic flow. J Atmos Sci
58(6):608-627. doi:10.1175/1520-0469(2001)058<0608:AFOAP $\mathrm{I}>2.0 . \mathrm{CO} ; 2$

Tang Q, Zhang X, Yang X, Francis JA (2013) Cold winter extremes in northern continents linked to Arctic sea ice loss. Environ Res Lett 8(1):14036. doi:10.1088/1748-9326/8/1/014036

Vihma T (2014) Effects of Arctic sea ice decline on weather and climate: a review. Surv Geophys 35(5):1175-1214. doi:10.1007/ s10712-014-9284-0

Walsh JE (2014) Intensified warming of the Arctic: causes and impacts on middle latitudes. Glob Planet Change 117:52-63. doi:10.1016/j.gloplacha.2014.03.003

Wu Q, Zhang X (2010) Observed forcing-feedback processes between Northern Hemisphere atmospheric circulation and Arctic sea ice coverage. J Geophys Res 115(D14):D14119. doi:10.1029/200 9JD013574

Wu B, Su J, Zhang R (2011) Effects of autumn-winter Arctic sea ice on winter Siberian High. Chin Sci Bull 56(30):3220-3228. doi:10.1007/s11434-011-4696-4

Wu B, Handorf D, Dethloff K, Rinke A, Hu A (2013) Winter weather patterns over Northern Eurasia and Arctic sea ice loss. Mon Weather Rev 141(11):3786-3800. doi:10.1175/ MWR-D-13-00046.1

Zhang X, Lu C, Guan Z (2012) Weakened cyclones, intensified anticyclones and recent extreme cold winter weather events in Eurasia. Environ Res Lett 7(4):44044. doi:10.1088/1748-9326/7/4/044044 